\title{
Prevalence of Polypharmacy among Egyptian Patients with Type 2 Diabetes Mellitus
}

\author{
Tayseer M. Metwally ${ }^{1 *}$ and, Hebatalla M. Aly ${ }^{2}$ \\ 'Department of Family Medicine, Faculty of Medicine, Suez University, Suez, Egypt \\ ${ }^{2}$ Department of Public Health, Community, Environmental and Occupational Medicine, Faculty of Medicine, \\ Suez Canal University, Ismailia, Egypt
}

\begin{abstract}
Background: Diabetes is a growing health problem in Egypt; Patients with diabetes often have coexisting chronic health conditions which increases the prevalence of multiple drug prescriptions. Aim: To identify the prevalence and predictors of polypharmacy among diabetic patients. Materials and Methods: An analytic cross-sectional record-based study was conducted in Suez governorate, Egypt as a single-center experience study on type 2 diabetic patients. The center is specialized in diabetic foot screening patients and serves all Suez diabetic patients. All 203 clinic medical records from December 2018 to December 2019 were included in the study. Results: Mean age of diabetic patients was $57.9 \pm 11.3$ years, $56.7 \%$ were females, $87.2 \%$ were living in urban areas, $76.3 \%$ were diagnosed with diabetes for more than 10 years. Half of the study participants (55.2\%) were on polypharmacy, older age, and medical history of either cardiovascular diseases or neuropathy were statistically significantly associated with increased frequency of their polypharmacy. Conclusions: This study provided us with an insight about the prevalence of polypharmacy among type 2 diabetic patients and further studies with larger sample sizes are needed to assess medications inappropriateness associated with polypharmacy in diabetic patients is recommended.
\end{abstract}

Key words: Prevalence; Diabetics; Hypoglycemic drugs; Antihypertensive drugs

\section{Introduction}

Diabetes is a growing health problem, Egypt is the ninth country with the highest number of diabetics worldwide, where 8.9 million adults from 20 to 79 years in 2019 registered to have diabetes ${ }^{(1)}$. Prevalence of diabetes in Egypt was 7.5million in 2013 and expected to jump up to 13.1 million by $2035^{(2)}$. There is no standard definition of polypharmacy, but it is often defined as the routine use of five or more medications. This includes over-the-counter prescription and/or traditional and complementary medicines used by a patient ${ }^{(3)}$. Another definition for polypharmacy is the medications that are not indicated, not effective, or constitutes a therapeutic duplication ${ }^{(4)}$. Patients with diabetes often have coexisting chronic health conditions such as hypertension, dyslipidemia, coronary artery disease, depression and chron- 
ic kidney disease, which require the use of multiple medications to treat those coexisting chronic conditions(5). All of these put patients with diabetes at a high risk of polypharmacy, with an estimated prevalence of $57 \%-84 \%$ of diabetic patients using five or more medications ${ }^{(6)}$. Management of hyperglycemia and its complications like diabetic neuropathy, retinopathy, nephropathy, coronary artery disease, peripheral arterial disease and stroke, with appearance of geriatric problems associated with diabetes like urinary incontinence, falls and cognitive impairment and side effects of drugs increase prevalence of polypharmacy among older adults with diabetes( 7$)$. Screening of polypharmacy among diabetics is important because polypharmacy increases the probability of the drug side effects, drug-drug interactions, duplication of therapy, decreases compliance of the patient to take medications and leads to uncontrolled hyperglycemia, associated with misinterpretation of drug side effects as new medical conditions leading to prescription of new medications to treat them, negative health consequences such as increased risk of hospitalization and medication error, higher risk of falling, poor functional status, poor quality of life, and high healthcare cost ${ }^{(8)}$. For all of these problems associated with polypharmacy and as there are not enough studies about polypharmacy among adults with diabetes living in Egypt and assessment of the specific factors that put patient at the risk of polypharmacy. The current study was conducted to identify the prevalence and risk factors of polypharmacy among diabetic patients in Suez governorate, Egypt.

\section{Materials and Methods}

An analytic cross-sectional record-based study was conducted in Suez governorate, Egypt. As a single center experience study on type 2 diabetic patients. This family medicine center is specialized in foot screening for diabetic patient and it serves all diabetic patients in Suez. All registered 203 medical records in the clinic from December 2018 to December 2019 were included in the study. From the medical file, all data related to socio-demographic characteristics and diabetes history were collected for analysis, this included: age, sex, marital status, occupation, family history of diabetes, duration of diabetes, smoking, diet and exercise, medical history, history of complications (retinopathy, neuropathy, renal and (VD). We revised drug list in each patient's file and documented all drugs used on daily basis for the patients, distributed medications according to their mode of action into antidiabetic drugs, antihypertensives, antidyslipidemic, acetyl salicylic acid, clopidogrel, drugs for neuropathy, vascular problems, angina, hyperuricemia, NSAIDs, peptic ulcer, vitamins ( $B$ \& D), calcium and miscellaneous. For data analysis, we wrote all trade names of the drugs according to their scientific name. We allocated drugs of diabetes, hypertension, and dyslipidemia according to classes according to the different mechanism of action and if they are in single or combination forms. The total number of drugs that were administered regularly on daily basis were counted for each patient with exclusion of drugs for acute problem such as antibiotics and local analgesics, creams, and eye drops.

\section{Statistical Analysis}

Data were analyzed using SPSS version 23. Qualitative data were presented as frequencies and percentages while quantitative data were presented as means and standard deviations. Differences between patients with polypharmacy and without were assessed by chi square test. P-values of $<0.05$ were considered significant. 


\section{Results}

Records of two hundred and three diabetic patients were included in the study to assess the frequency of polypharmacy among diabetic patients. Characteristics of diabetics and diabetes mellitus history are shown in (Table 1).

\begin{tabular}{|c|c|c|c|}
\hline \multicolumn{4}{|c|}{ Table 1: Characteristics of diabetic patients $(n=203)$} \\
\hline Socio-demographic characte & tics & Frequency & Percentage \\
\hline \multirow{4}{*}{ Age in years } & $25-45$ & 28 & $13.8 \%$ \\
\hline & $>45-65$ & 127 & $62.6 \%$ \\
\hline & $>65$ & 48 & $23.6 \%$ \\
\hline & Mean \pm SD & \multicolumn{2}{|c|}{$57.9 \pm 11.3$} \\
\hline \multirow{2}{*}{ Gender } & Male & 88 & $43.3 \%$ \\
\hline & Female & 115 & $56.7 \%$ \\
\hline \multirow{2}{*}{ Marital status } & Married & 148 & $72.9 \%$ \\
\hline & Others & 55 & $27.1 \%$ \\
\hline \multirow{2}{*}{ Residency } & Urban & 119 & $88.2 \%$ \\
\hline & Rural & 24 & 11.8 \\
\hline \multirow{4}{*}{ Occupation } & Active worker & 62 & $30.5 \%$ \\
\hline & Retired & 44 & 21.7 \\
\hline & Housewife & 94 & $46.3 \%$ \\
\hline & Not working & 3 & $1.5 \%$ \\
\hline Family history of DM & Yes & 167 & $82.3 \%$ \\
\hline \multirow{4}{*}{ Duration of DM } & $<10$ years & 48 & $23.7 \%$ \\
\hline & $10-20$ years & 103 & $50.7 \%$ \\
\hline & $>20$ years & 52 & $25.6 \%$ \\
\hline & Mean \pm SD & \multicolumn{2}{|c|}{$16.1 \pm 9.1$} \\
\hline Control of DM & controlled & 60 & $29.6 \%$ \\
\hline Diet control & Yes & 93 & $45.8 \%$ \\
\hline Exercise & Yes & 13 & $6.4 \%$ \\
\hline Smoking & Yes & 26 & $12.8 \%$ \\
\hline Neuropathy & Yes & 166 & $81.8 \%$ \\
\hline Cardiovascular diseases & Yes & 109 & $53.7 \%$ \\
\hline Renal disease & Yes & 13 & $6.4 \%$ \\
\hline
\end{tabular}

Only $29 \%$ of diabetics were controlled according to their random blood glucose results. Forty six percent admitted to be on a controlled diet and only $6.4 \%$ practiced walking as an exercise. Fortunately, $84 \%$ were non-smokers. Body mass index was calculated to 156 of diabetics (mean $34.5 \pm 8.1 \mathrm{~kg} / \mathrm{m}^{2}$ ) and random blood sugar was performed to 175diabetics (mean $238.1 \pm 117.1 \mathrm{mg} / \mathrm{dl}$ ). The total number of drugs administered regularly on daily basis was totaled for each patient with exclusion of drugs for acute problems. Half of the patients (55.2\%) were on polypharma- cy. The median of number of the daily administered drugs was 5 drugs, but patients were taking drugs ranging from none to 16 drugs per day (Table 2). Table 3 shows the proportion of the most common drug classes used by the study group, Insulin injection was used in $64.5 \%$, followed by oral hypoglycemic drugs (61.1\%), antihypertensive drugs (61.1\%), aspirin $(38.4 \%)$, oral vitamin B (33.3\%), antidyslipidemic drug (30.4\%), drugs for neuropathy (29.1\%), vascular drugs (20.4\%), drugs for gout (10.3\%), clopidogrel (9.9\%), calcium (9.8\%), drug for angina (8.3\%) and 
drugs for peptic ulcer in (7.8\%). For oral antidiabetics, the most commonly used drugs were biguanide and sulfonylurea (22.1\% and $15.6 \%$ respectively) as single oral drug, followed by the most frequent combination form biguanide with DPP4 inhibitors (16.4\%), tailed by biguanide and sulphonylurea either as a single drug or as a single combination tablet ( $9.8 \%$ for both categories).

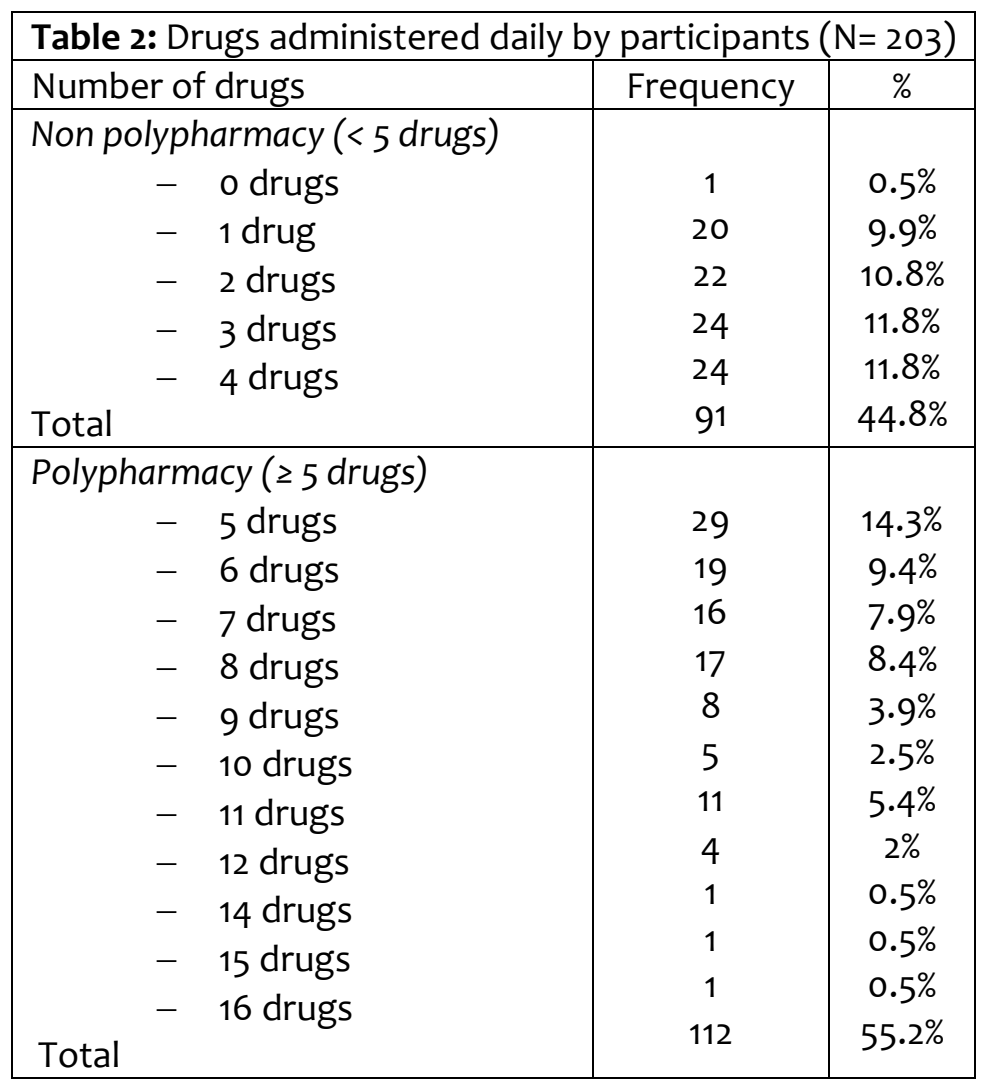

Most used antihypertensive drugs were Beta Blockers(15.6\%), followed by ACEI (9\%) and diuretics (8.2\%), and (diuretic with beta blockers) or (diuretic with ACEI) as a single combination tablet (6.6\% for each category).Statin as a single drug was the commonest antidyslipidemic drug (93.4\% of patients), trailed by statin with ezetimibe combination (9.8\%) (Table 4). Patients' characteristics and diabetes history were compared between polypharmacy and non-polypharmacy groups. Regarding studied characteristics there were no statistical significance, except for age, history of cardiovascular diseases (OR = 2.4; $p=0.002$ ) and expressing neuropathy $(\mathrm{OR}=2.2 ; p=0.031)$ which has increased the frequency of polypharmacy (Table 5).

\section{Discussion}

Two hundred and three diabetic patients were included in this study to assess the prevalence of polypharmacy among diabetic patients. $62.6 \%$ of them were in the age group between 45 to 65 years old which is different from other studies where most studies on polypharmacy was noted in older adults. Also, $56 \%$ of the study subjects were females, $88.2 \%$ of them lived in urban areas, $50.2 \%$ were diagnosed with diabetes for 10 to 20 years, neuropathy and cardiovascular complication were found in $85.8 \%$ and $53.7 \%$ of patients, respectively. According to the definition of WHO, polypharmacy means to use five or more medications. 


\begin{tabular}{|l|c|c|}
\hline \multicolumn{3}{|c|}{ Table 3: Drug classes (\%) prescribed in type 2 diabetic patients (N=203) } \\
\hline Drug & Frequency & $\%$ \\
\hline Insulin injection & 131 & $64.5 \%$ \\
\hline Oral hypoglycemic drugs & 122 & $61.1 \%$ \\
\hline Anti-hypertensive drugs & 122 & $61.1 \%$ \\
\hline Acetyl salicylic acid & 79 & $38.4 \%$ \\
\hline Oral vitamin B & 68 & $33.3 \%$ \\
\hline Anti-dyslipidemic drugs & 61 & $30.4 \%$ \\
\hline Drugs for neuropathy & 60 & $29.4 \%$ \\
\hline Drugs for vascular & 41 & $20.1 \%$ \\
\hline Drugs for gout & 21 & $10.3 \%$ \\
\hline Clopidogrel & 20 & $9.9 \%$ \\
\hline Calcium & 20 & $9.8 \%$ \\
\hline Anti-angina drugs & 18 & $8.3 \%$ \\
\hline Peptic ulcer drugs & 16 & $7.8 \%$ \\
\hline NSAIDs & 11 & $5.4 \%$ \\
\hline Vitamin D & 6 & $2.9 \%$ \\
\hline Others & 74 & $36.5 \%$ \\
\hline
\end{tabular}

The frequency of polypharmacy among type 2 DM patients was more than half (55.2\%), which is elevated and consistent with other studies similar to a Saudi Arabia study which showed that nearly with $78 \%$ of study subjects were on polypharmacy ${ }^{(8)}$. A previous study on Japanese patients reported that $64.6 \%$ were using six or more medications $(9)$. In the United States and Brazil it was $54 \%\left({ }^{10)}\right.$ and $56.5 \%{ }^{(11)}$ respectively. In another study in Egypt for the 60 years old and over, it was stated that the prevalence of polypharmacy was $85.3 \%$ (12). The total number of drugs that are administered regularly on a daily basis was counted for each patient; median of the number of drugs administered daily was five, ranging from none to 16 drugs daily as three patients only were noncompliant and did not take their prescribed medications in this study. In a study in the UK, $84 \%$ were being prescribed four or more medications, They were being prescribed drugs in range from none to 17 drugs( $^{(6)}$, and in Brazil also amplitude of none to 17 medications documented in use per person ${ }^{(11)}$, which is consistent with our results taking in consideration that this study was for all age groups not elder- ly patients only like most of the other studies.

\section{Drug categories}

Main drug categories frequently used by diabetic patients in this study were Insulin injections by $64.5 \%$, Oral anti-diabetics $60.1 \%$, Anti-hypertensive drugs $60.1 \%$, aspirin $38.4 \%$, vitamin B $33.3 \%$, antidyslipidemic drug $30.4 \%$, drug for neuropathy $29.1 \%$, vascular drugs $20.4 \%$, drugs for gout $10.3 \%$, clopidogrel $9.9 \%$, calcium $9.8 \%$, drug for angina $8.3 \%$ and drugs for peptic ulcer in 7.8\%. In a Chinese study, the commonest prescription was antidiabetic agents $79.8 \%$ were on oral antidiabetic drugs and $74.8 \%$ were on insulin, $36.9 \%$ were on antithrombotic agents and $69.5 \%$ were on lipid modifying agents(13). In another study, 59\% were prescribed anti-platelet drugs for cardiovascular disease prevention including aspirin, clopidogrel, dipyridamole, and residents, $41 \%$ were on statin therapy ${ }^{(6)}$, In Korea, the prevalence of statins and aspirin users was $52 \%$ and $32 \%$ respectively ${ }^{(14)}$ indicating the need to follow up and manage dyslipidemia to prevent further complications of our DM patients. 


\begin{tabular}{|c|c|c|}
\hline \multicolumn{3}{|c|}{$\begin{array}{l}\text { Table 4: prescription status of oral hypoglycemic, antihypertensive and } \\
\text { anti-dyslipidemic drugs }\end{array}$} \\
\hline \multicolumn{2}{|c|}{ Oral hypoglycemic drugs } & \multirow{2}{*}{ No. (\%) } \\
\hline $1^{\text {st }}$ drug & $2^{\text {nd }} d r u g$ & \\
\hline Biguanide & & $27(22.1)$ \\
\hline Sulfonylurea & & $19(15.6)$ \\
\hline Biguanide/DPP4I & & $20(16.4)$ \\
\hline Biguanide/Sulfonylurea & & $12(9.8)$ \\
\hline Biguanide & Sulfonylurea & $12(9.8)$ \\
\hline meglitinide & & $3(2.5)$ \\
\hline SGLT2I & & $3(2.5)$ \\
\hline Biguanide & DPP4I/ Biguanide & $3(2.5)$ \\
\hline Sulfonylurea & DPP4I/Biguanide & $3(2.5)$ \\
\hline DPP4I/Biguanide & Sulfonylurea/Biguanide & $3(2.5)$ \\
\hline Biguanide & Sulfonylurea / Biguanide & $2(1.6)$ \\
\hline DPP4I/Biguanide & Sulfonylurea /pioglitazone & $2(1.6)$ \\
\hline DPP4I/Biguanide & SGLT2I & $2(1.6)$ \\
\hline others & & $10(8.2)$ \\
\hline \multicolumn{2}{|c|}{ Anti-hypertensive drugs } & \multirow{2}{*}{ No. $(\%)$} \\
\hline $1^{\text {st }}$ drug & $2^{\text {nd }} d r u g$ & \\
\hline BB & & $19(15.6)$ \\
\hline ACEI & & $11(9)$ \\
\hline Diuretic & & $10(8.2)$ \\
\hline BB/Diuretic & & $8(6.6)$ \\
\hline ACE/Diuretic & & $8(6.6)$ \\
\hline ARB & & $5(4.1)$ \\
\hline Diuretic/ARB & & $5(4.1)$ \\
\hline $\mathrm{BB}$ & Diuretic/ARB & $5(4.1)$ \\
\hline CCB/ARB & & $4(3.3)$ \\
\hline BB & Diuretic & 4(3.3) \\
\hline BB & ARB & 4(3.3) \\
\hline $\mathrm{CCB}$ & & $3(2.5)$ \\
\hline $\mathrm{BB}$ & ACEI & $3(2.5)$ \\
\hline others & & $33(27)$ \\
\hline \multicolumn{2}{|c|}{ Antidyslipidemic drugs } & \multirow{2}{*}{ No. (\%) } \\
\hline $1^{\text {st }}$ drug & $2^{\text {nd }} d r u g$ & \\
\hline Statins & & $57(93.4)$ \\
\hline Ezetimibe/Statin & & $6(9.8)$ \\
\hline Statin & Statin & $4(6.6)$ \\
\hline Fibrates & & $3(5)$ \\
\hline Ezetimibe & & $1(1.6)$ \\
\hline
\end{tabular}

In a study in Romania aimed to evaluate the use of polypharmacy in type 2 diabetes mellitus vs. non-diabetes patients. In the T2DM group, the most common drug classes prescribed were statins $68.25 \%$, diuretics $60.31 \%$, beta-blockers $59.93 \%$, and ACE inhibitors 50.79\%. Anti-aggregate
48.43\%, PPI 47.62, antidiabetic drugs $44.44 \%$, CCB $41.28 \%$, anticoagulant $38.46 \%$, ARB $26.98 \%(15)$. In another study in Brazil $40 \%$ were using cardiovascular drugs, $35.4 \%$ using alimentary and diabetic medications, $10.2 \%$ using drugs for nervous system. The more frequent therapeutic clas- 
ses in use were medications for DM, agents acting in the rennin angiotensin system, diuretics, lipid modifier agents, and thrombolytic agents. The more frequent medications in use were metformin, losartan, glibenclamide, and simvastatin ${ }^{(11)}$

Risk factors for polypharmacy

In our study, there was no significant relationship between sex and polypharmacy which was inconsistent with the Saudi Arabia study results which stated that women was more likely to have polypharmacy than men ${ }^{(8)}$, this may be related to other associated chronic illnesses more common in gulf women than Egyptians. The difference between polypharmacy group and non-polypharmacy group regarding studied characteristics was statistically significant for age, which has increased frequency of polypharmacy which is consistent with many studies as the study in Saudi Arabia(8)and in Japan which stated that older adults with diabetes are at a greater risk of receiving more drugs than those without diabetes, the rate of polyphamacy defined $\geq 6$ internal medications, was $6.7 \%(9)$, and in Brazil( ${ }^{(11)}$.

\begin{tabular}{|c|c|c|c|c|}
\hline \multicolumn{5}{|c|}{$\begin{array}{l}\text { Table 5: Patients characteristics and diabetes history among polypharmacy } \\
\text { and non-polypharmacy groups }\end{array}$} \\
\hline \multicolumn{2}{|c|}{ Socio-demographic characteristics } & $\begin{array}{l}\text { Polypharmacy } \\
\text { No. (\%) }\end{array}$ & $\begin{array}{c}\text { Non- polypharmacy } \\
\text { No. (\%) }\end{array}$ & $p$-value \\
\hline \multirow{3}{*}{ Age in years } & $25-45$ & $11(9.8 \%)$ & $17(18.7 \%)$ & \multirow{3}{*}{$0.037^{1 *}$} \\
\hline & $>45-65$ & $68(60.7 \%)$ & $59(64.8 \%)$ & \\
\hline & $>65$ & $33(29.5 \%)$ & $15(16.5 \%)$ & \\
\hline \multirow{2}{*}{ Gender } & Male & $53(47 \cdot 3 \%)$ & $35(38.5 \%)$ & \multirow{2}{*}{$0.205^{1}$} \\
\hline & Female & $59(52.7 \%)$ & $56(61.5 \%)$ & \\
\hline \multirow{2}{*}{ Marital status } & Married & $82(73.2 \%)$ & $65(71.4 \%)$ & \multirow{2}{*}{$0.777^{1}$} \\
\hline & Others & $30(26.8 \%)$ & $26(28.6 \%)$ & \\
\hline \multirow[b]{2}{*}{ Residency } & Urban & $100(89.3 \%)$ & $79(86.8 \%)$ & \multirow{2}{*}{$0.874^{1}$} \\
\hline & Rural & $12(10.7 \%)$ & $12(13.2 \%)$ & \\
\hline \multirow{4}{*}{ Occupation } & Active worker & $37(33 \%)$ & $25(27.5 \%)$ & \multirow{4}{*}{$0.279^{1}$} \\
\hline & Retired & $28(25 \%)$ & $16(17.6 \%)$ & \\
\hline & Housewife & $46(41.1 \%)$ & $48(52.7 \%)$ & \\
\hline & Not working & $1(0.9 \%)$ & $2(2.2 \%)$ & \\
\hline \multirow{3}{*}{ Duration of DM in years } & $<10$ & $24(21.4 \%)$ & $24(26.4 \%)$ & \multirow{3}{*}{$0.061^{1}$} \\
\hline & $10-20$ & $52(46.4 \%)$ & $51(56 \%)$ & \\
\hline & $>20$ & $36(32.1 \%)$ & 16 (17.6\%) & \\
\hline \multirow{2}{*}{ Family history } & Yes & $95(84.9 \%)$ & $72(79.1 \%)$ & \multirow{2}{*}{$0.513^{1}$} \\
\hline & No & $17(15.2 \%)$ & $19(20.9 \%)$ & \\
\hline \multirow{2}{*}{ Control of DM } & Yes & $36(32.7 \%)$ & $24(26.4 \%)$ & \multirow{2}{*}{$0.327^{1}$} \\
\hline & No & $74(67.3 \%)$ & $67(73.6 \%)$ & \\
\hline \multirow{2}{*}{ Diet control } & Yes & $46(49.5 \%)$ & $47(50.5 \%)$ & \multirow{2}{*}{$0.164^{1}$} \\
\hline & No & $64(59.3 \%)$ & $44(40.7 \%)$ & \\
\hline \multirow{2}{*}{ Smoking } & Yes & $11(42.3 \%)$ & $15(57.7 \%)$ & \multirow{2}{*}{$0.173^{1}$} \\
\hline & No & $99(56.6 \%)$ & $76(43.4 \%)$ & \\
\hline \multirow{2}{*}{ Exercise } & Yes & $9(69.2 \%)$ & $4(30.8 \%)$ & \multirow{2}{*}{$0.277^{1}$} \\
\hline & No & $101(53.7 \%)$ & $87(46.3 \%)$ & \\
\hline \multirow{2}{*}{ Cardiovascular diseases } & Yes & $71(64 \%)$ & $38(41.8 \%)$ & \multirow{2}{*}{$0.002^{1^{*}}$} \\
\hline & No & $40(36 \%)$ & $53(58.2 \%)$ & \\
\hline \multirow{2}{*}{ Neuropathy } & Yes & $97(58.4 \%)$ & $68(41.2 \%)$ & \multirow{2}{*}{$0.031^{1^{*}}$} \\
\hline & No & $15(40.5 \%)$ & $23(60.5 \%)$ & \\
\hline \multirow{2}{*}{ Renal disease } & Yes & $8(7.3 \%)$ & $5(5.5 \%)$ & \multirow{2}{*}{$0.598^{1}$} \\
\hline & No & $101(92.7 \%)$ & 86 (94.5\%) & \\
\hline
\end{tabular}

${ }^{1}$ Chi square test; "Statistically significant at $p<0.05$. 
On the other hand, polypharmacy was not significantly associated with age in another study in Egypt (12), This may be explained that almost all other studies participants were elderly only which is different from this study which encompassed all age groups. Longer duration of diabetes was not associated with polypharmacy in this study which is inconsistent with a study in the UK ${ }^{(13)}$, in Italy, polypharmacy was associated with duration of more than 5 years in T2DM patients ${ }^{(16)}$. Another study in Brazil proved that polypharmacy was associated with more than 10 years duration of diabetes ${ }^{(11)}$, this may be attributed to the presence of other disease with diabetes or occurrence of complications with diabetes which obligate patients to take more drugs. History of cardiovascular diseases and history of neuropathy has increased frequency of polypharmacy in our study which is consistent with many studies. In a study in Egypt, for elderly residence co-morbidity were significant predictors of polypharmacy ${ }^{(12)}$, In Brazil also co-morbidities was associated with polypharmacy. Medications acting on the cardiovascular system was the most utilized ones ${ }^{(11)}$, A study for polypharmacy in elderly in Finland showed that cardiovascular medications were the most commonly used drugs ${ }^{(17)}$, Another study showed that the most common prescription drugs among elderly were cardiovascular $24.8 \%$ and CNS $22.7 \%$ medications $^{(18)}$.

\section{Hypoglycemic drugs}

Among participating diabetic patients three patients (1.5\%) did not use treatment at all for diabetes as they were newly diagnosed and non-compliant with the prescribed drugs; 69 patients (34\%) use oral anti-diabetics only; 78 patients use insulin only (38.4\%); and 53 (26.1\%) use both insulin and oral hypoglycemic drugs which is different from a study in Korea where $68.2 \%$ with oral hypoglycemic agents only, $5.3 \%$ with insulin only, and $19.2 \%$ with both insulin and oral hypoglycemic agents(19) this may be explained that the majority of Egyptian patients are poor and can't buy the new generations of oral hypoglycemic drugs as it is very expensive in comparison to premixed insulin which they can take from the general hospitals mostly free. The most used single oral antidiabetic drug class was biguanide (metformin) in $22.1 \%$ of cases. $15.6 \%$ use sulphonylurea, this is concomitant with the result of a study in the UK primary care, which confirmed that metformin prescribing peaked at $83.6 \%$, while sulfonylureas prescribing reached $41.4 \%$. Both remained, however, the most commonly used pharmacological treatments as first-line agents and add-on therapy(20), but in this study biguanide/DPP4 inhibitors combination drug in $16.4 \%$ of patients becomes the most prevalent oral hypoglycemic combination drug followed by the combination of biguanide and sulphonylurea either as taking each as a single drug or as a single combination tablet in $9.8 \%$ for each group, In Japan among hospitalized patients with T2DM, DPP4 inhibitors were the most commonly used hypoglycaemic medications ${ }^{(9)}$ Gliptins have become the second most common class of antidiabetic medication added to metformin therapy, with a usage of $26.9 \%(20)$, and as first combination used in frequency in another study ${ }^{(19)}$

\section{Antihypertensive drugs}

For hypertension in our study, $60.1 \%$ were using antihypertensive drugs. The most frequent single drug class used was beta blockers in $21.2 \%$, followed by ACE $9 \%$, diuretic $8.2 \%$, then combination therapy. The commonest combination form used was (beta blocker with diuretic) in $6.6 \%$ of patients followed by $(\mathrm{ACl}$ with diuretic) in 
6.6\%. This is different from a study which revealed that $53 \%$ of patients were treated with a diuretic, $48 \%$ with an ARB, (47\%) with beta blockers, $45 \%$ with CCB and $29 \%$ with an $\mathrm{ACEl}^{(21)}$, another study proved that diuretics remained the most commonly used antihypertensive drug class but this was during the period between 2001 and $2010^{(22)}$.

\section{Conclusion}

We conclude that elderly diabetic patients with longer duration of diabetes, cardiovascular diseases and neuropathy are associated with higher risks of polypharmacy, further studies with larger sample sizes to assess the inappropriate medications associated with polypharmacy in diabetic patients are recommended.

\section{Study limitations}

The study is a record-based study, so some data were missing for some patients as BMI and random blood sugar level, Retinal complications could not be confirmed as fundus examination has not been performed or registered within the files but these data did not affect the main findings of the study.

\section{Conflicts of Interest}

There are no conflicts of interest.

Financial support and sponsorship

This research did not receive any specific grant from funding agencies in the public, commercial, or not-for-profit sectors.

\section{Abbreviations}

World Health Organization (WHO), International Diabetes Federation (IDF), Beta blockers (BB), Angiotensin converting enzyme inhibitors (ACE inhibitor), Angiotensin receptor blocker (ARB), Calcium channel blockers (CCB), Dipeptidyl peptidase-4 inhibitor (DPP4I), Sodium-glucose Cotransporter-2 Inhibitors (SGL2I), Proton
Pump Inhibitor (PPI), Central Nervous System (CNS), Type 2 Diabetes Mellitus (T2DM), Body Mass Index (BMI).

\section{References}

1. Elflein J. Countries with the highest number of diabetics worldwide in 2019 [Internet]. 2019. Available from: https://www.statista.com/statistics/28 1082/countries-with-highest-numberof-diabetics/

2. Hegazi R, El-Gamal M, Abdel-Hady N, Hamdy O. Epidemiology of and Risk Factors for Type 2 Diabetes in Egypt. Ann Glob Heal [Internet]. 2015; 81 (6): 814-20. Available from: http:// dx.doi.org/10.1016/j.aogh.2015.12.011

3. Organization WH. Medication Safety in Polypharmacy [Internet]. World Health Organization technical report series. 2019. Available from: https:// apps.who.int/iris/bitstream/handle/106 65/325454/WHO-UHC-SDS-2019.11eng.pdf?ua=1

4. Strehl V. Wavelet Transformationen in der Bildverarbeitung Script. 2013; 13 (1): 1-11.

5. RACGP. General practice management of type 2 diabetes [Internet]. Royal Australian College of General Practitioners. 2016. 192 p. Available from: https://www.racgp.org.au/ download/Documents/Guidelines/Diab etes/2015diabetesmanagement.pdf

6. Gadsby R, Galloway M, Barker P, Sinclair A. Prescribed medicines for elderly frail people with diabetes resident in nursing homes-issues of polypharmacy and medication costs. Diabet Med. 2012;29:136-9.

7. Peron EP, Ogbonna KC, Donohoe KL. Antidiabetic medications and polypharmacy. Clin Geriatr Med. 2015; 31 (1): 17-27.

8. Alwhaibi $M$, Balkhi $B$, Alhawassi TM, Alkofide $\mathrm{H}$, Alduhaim N, Alabdulali R, et al. Polypharmacy among patients with diabetes: a cross-sectional retrospective study in a tertiary hospital in Saudi Arabia. BMJ Open. 
2018; 8:20852.

9. Horii T, Iwasawa M, Kabeya Y, Atuda K. Polypharmacy and oral antidiabetic treatment for type 2 diabetes characterised by drug class and patient characteristics: A Japanese database analysis. Sci Rep [Internet]. 2019;9(1):1-6. Available from: http://dx.doi.org/10.1038/s41598-01949424-

10. Grant RW, Devita NG, Singer DE, Meigs JB. Polypharmacy and Medication Adherence in Patients With Type 2 Diabetes. 2003.

11. da Silva MRR, Diniz LM, Dos Santos $J B R$, Reis EA, da Mata AR, de Araújo $V E$, et al. Drug utilization and factors associated with polypharmacy in individuals with diabetes mellitus in Minas Gerais, Brazil. Cienc e Saude Coletiva. 2018;23(8):2565-74.

12. Eltaher SM, Araby EM. Sheref $M$. Eltaher, et al Prevalence And Factors Associated With Polypharmacy Among Elderly Persons. Vol. 37, Egy J Commun Med. 2019.

13. Li J, Chattopadhyay K, Xu M, Chen Y, Hu $F$, Wang $X$, et al. Prevalence and predictors of polypharmacy prescription among type 2 diabetes patients at a tertiary care department in Ningbo, China: A retrospective database study. 2019;

14. Suk JH, Lee CW, Son SP, Kim MC, Ahn $\mathrm{JH}$, Lee KJ, et al. Current Status of Prescription in Type 2 Diabetic Patients from General Hospitals in Busan. 2014;

15. Dobrică EC, Găman MA, Cozma MA, Bratu OG, Stoian AP, Diaconu CC. Polypharmacy in type 2 diabetes mellitus: Insights from an internal medicine department. Med [Internet]. 2019; 55 (8). Available from: http://www/ncbi.nlm.nih.gov/pubmed/
31382651

16. Kirchmayer $U$, Mayer F, Basso M, De Cristofaro R, Mores N, Cappai G, et al. Polypharmacy in the elderly: A population based cross-sectional study in Lazio, Italy.

17. Linjakumpu T, Hartikainen S, Klaukka T, Veijola J, Kivelä S-L, Isoaho R. Use of medications and polypharmacy are increasing among the elderly. Vol. 55, $\mathrm{J}$ Clin Epidemiol. 2002.

18. Barat I, Andreasen F, Damsgaard EMS. Pharmaco epidemiology and prescription The consumption of drugs by 75year-old individuals living in their own homes. Eur J Clin Pharmacol. 2000;56:501-9.

19. Suk JH, Lee CW, Son SP, Kim MC, Ahn $\mathrm{JH}$, Lee KJ, et al. Current status of prescription in type 2 diabetic patients from general hospitals in Busan. Diabetes Metab J. 2014;38(3):230-9.

20. Sharma M, Nazareth I, Petersen I. Trends in incidence, prevalence and prescribing in type 2 diabetes mellitus between 2000 and 2013 in primary care: A retrospective cohort study. BMJ Open. 2016;6(1).

21. Levi-Marpillat N, Macquin-Mavier I, Tropeano A-I, Parati G, Maison P. Antihypertensive drug classes have different effects on short-term blood pressure variability in essential hypertension. Hypertens Res. 2014; 37: 585-90.

22. Gu Q, Burt VL, Dillon CF, Yoon S. Trends in antihypertensive medication use and blood pressure control among united states adults with hypertension: The national health and nutrition examination survey, 2001 to 2010. Circulation. 2012;126(17):2105-14. 